\title{
Gene Expression of the RANK/RANKL/OPG System on a Three-Dimensional Culture of Human Periodontal Fibroblasts Under Continuous Compression
}

\section{Andrea Cristina Baptista Coelho de Faria*, Antonio Carlos Aloise and Lidya Masako Ferreira}

Surgical Translational Graduate Program at Unifesp, Rua Botucatu, São Paulo- SP,

Brazil

*Corresponding Author: Andrea Cristina Baptista Coelho de Faria, Surgical Translational Graduate Program at Unifesp, Rua Botucatu, São Paulo- SP, Brazil.
Received: August 20, 2021

Published: September 25, 2021

(C) All rights are reserved by Andrea Cristina

Baptista Coelho de Faria., et al.

\begin{abstract}
Introduction: The cultivation of periodontal ligament fibroblasts, associated with the simulation of compression or tension on the cell, enables the analysis of changes in morphology and identification of molecules and protein expression. The system formed by the receptor activator of nuclear factor $\kappa \mathrm{B}$ (RANK), receptor activator of nuclear factor $\kappa \mathrm{B}$ ligand (RANKL), and osteoprotegerin (OPG) is directly linked to bone remodeling, in the formation and reabsorption of bone tissue.

Objective: To evaluate gene expression of RANK \RANKL and OPG in a three-dimensional culture of human periodontal fibroblasts in chitosan and xanthan membranes.

Method: Immortalized human periodontal fibroblasts were used. Cells were randomized into two groups: control group (CG), with three-dimensional cultivation without application of load for 6h, and experimental group (EG1, EG2, EG3 and EG4), with threedimensional cultivation with application of $4,12,24$, and $48 \mathrm{~g} / \mathrm{cm}^{2}$ loads for 6 h, respectively. Cell mRNA was extracted from all groups and evaluated through real-time polymerase chain reaction (RT-PCR) and TaqMan probe. Results: No RANK / RANKL expression was detected, however OPG expression occurred, which was significantly higher in EG2 compared to CG, EG1, EG3 and EG4.

Conclusion: The $12 \mathrm{~g} / \mathrm{cm}^{2}$ load applied onto a three-dimensional culture of periodontal fibroblasts for 6 hours displayed greater OPG expression.
\end{abstract}

Keywords: RANK; RANKL; OPG; RT-PCR

\section{Introduction}

In recent years, techniques for culturing several types of cells in vitro have enabled the analysis of models which simulate certain situations and characteristics akin to those occurring in vivo. Among the advantages of cell culture are the fixed parameters, such as temperature control, oxygenation, osmolarity, $\mathrm{pH}$ and $\mathrm{CO}_{2}$ control [28]. Cells that reside, proliferate, and differentiate in living organisms are arranged in a three-dimensional (3D) microenvironment known as the extracellular matrix (ECM). The ECM is a complex structure, formed by components synthesized and deposited on the outer surface of the cell (collagens, glycoproteins, and proteoglycans), which provide structural and functional integrity

Citation: Andrea Cristina Baptista Coelho de Faria., et al. "Gene Expression of the RANK/RANKL/OPG System on a Three-Dimensional Culture of Human Periodontal Fibroblasts Under Continuous Compression". Acta Scientific Dental Sciences 5.10 (2021): 91-99. 
for connective tissues and organs [4,6]. Several attempts have been made to establish a culture system that mimics in vivo interactions between cells and the ECM. To reconstitute the in vivo environment, cells must adhere and grow properly in three-dimensional (3D) scaffolds or substrates, thus facilitating cell-cell contact and expression of the expected phenotype [7,22]. Regarding physiology, shape, and environment, cells cultured in a 3D matrix represent more closely the natural structure and function of tissues in vivo $[5,23,33]$.

Mechanotransduction is the process of producing a biochemical reaction from a mechanical stimulus. Biochemical chain reactions induced by mechanical stimuli act at cellular level and can cause, among other effects, inhibition of apoptosis, increased cell proliferation, and altered cell migration. For example, when chewing, the mechanical forces transferred onto the teeth are dissipated through the periodontal ligament. Histological studies of the tissue around the teeth, have shown that this force exerts tension associated with bone formation, as well as bone resorption inducing compression [21]. Research in the field of cell biology often aims to identify which molecules are present in this cell differentiation process while subjected to different types of loads due to tooth movement. High loads can reduce cell viability, causing apoptosis or significant tissue damage, whereas periodontal tissue cells can develop osteoblastic activity when subjected to mechanical stress [32]. Osteoclastogenesis is an indicator of such bone remodeling, responsible for cell differentiation, proliferation, and expression of the extracellular matrix [27].

Molecules involved in this bone remodeling are osteoprotegerin $(\mathrm{OPG})$, receptor activator of nuclear factor $\kappa \mathrm{B}$ (RANK), and receptor activator of nuclear factor $\kappa \mathrm{B}$ ligand (RANKL). The RANKL/OPG/ RANK is an important signaling path, which plays a key role in bone resorption and can be modified by osteoblasts, cementoblasts and osteoclasts $[13,20]$. RANKL facilitates bone resorption through osteoclasts and activates bone maturation [34]. Osteoblasts also produce OPG, which acts as a receptor for RANKL and subsequently inhibits bone resorption.

Studies that evaluated cellular events in osteoclastogenesis, used polymerase chain reaction (PCR) as an instrument for precise analysis. This technique has revolutionized research in molecular biology, as it enables the obtention of enough genetic material to detect and analyze the targeted sequence under study [18,27].
The purpose of the three-dimensional substrate culture system is to promote cell propagation by using 3D matrix scaffolds. This study model involving mechanotransduction, through continuous compression of cells, enables the analysis of changes in their morphology and identification of molecules and protein expression (Figure 1).

\section{Continuous Compression}

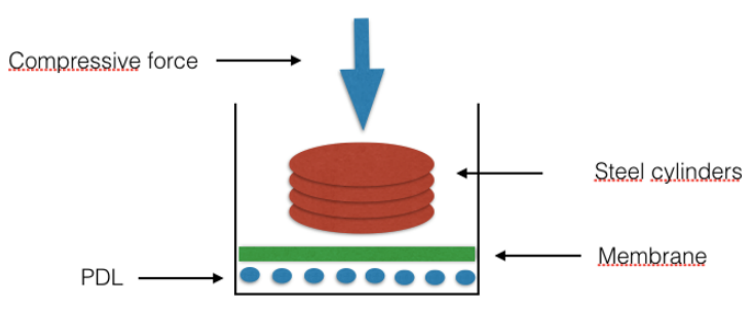

Figure 1: Schematic of the continuous compression forces applied onto chitosan and xanthan membranes, representing the three-dimensional model used.

\section{Materials and Methods}

\section{Materials}

Chitosan-xanthan scaffolds were prepared using chitosan at an 82\% degree of deacetylation (Sigma-Aldrich Co; Saint Louis, MO, USA), xanthan gum (Sigma-Aldrich Co.; Saint Louis, MO, USA, with pyruvic acid content higher than 1.5\%), Pluronic ${ }^{\natural}$ F127 (SigmaAldrich Co.; Saint Louis, MO, USA), and water, purified in a Milli$\mathrm{Q}^{\circledR}$ system (Millipore). All other reagents used were of analytical grade.

\section{Scaffold preparation}

Dense and porous Ch-X matrices were prepared as per adaptations of the procedures described by Bellini., et al. [15], at a Ch:X mass ratio of $1: 1$. The $\mathrm{Ch}-\mathrm{X}$ polyelectrolyte complex was prepared using 1\% (w/v) solution of chitosan (in aqueous acetic acid solution, $1 \% \mathrm{v} / \mathrm{v}$ ) and xanthan gum (aqueous solution). Using a peristaltic pump (TE-BP-01), $200 \mathrm{~mL}$ of chitosan solution at a flow rate of $9 \mathrm{~mL} / \mathrm{min}$ was added into a jacketed stainless steel reactor (internal diameter of $10 \mathrm{~cm}$ and height of $20 \mathrm{~cm}$ ) containing 200 $\mathrm{mL}$ of xanthan gum solution. The temperature was kept at $37^{\circ} \mathrm{C}$, 
in a TE-393-80L oven (TECNAL), throughout the process, and the mixture stirred at $1000 \mathrm{rpm}$, with a mechanical stirrer equipped with a marine-type propeller $(2.5 \mathrm{~cm}$ radius). After the addition of the chitosan solution, the system was agitated at $1000 \mathrm{rpm}$ for 10 minutes. To obtain porous matrices of Pluronic ${ }^{\natural}$, F127 was added to the xanthan solution prior to the addition of chitosan. After that, the mixture was transferred to two $15 \mathrm{~cm}$ polystyrene Petri dishes and the solvent was evaporated in an oven with air circulation at $37^{\circ} \mathrm{C}$ for 24 or $48 \mathrm{~h}$, for dense or porous formulations, respectively. After that, the scaffolds were washed with water for $30 \mathrm{~min}$ (200 $\mathrm{mL}$, twice), $10 \mathrm{mM}$ HEPES buffer for 20 minutes (150 mL, twice) and water for another 15 minutes. Final drying was conducted at room temperature for dense formulations and at $37^{\circ} \mathrm{C}$ for $24 \mathrm{~h}$ for porous formulations. For the biological tests, the scaffolds were sterilized with ethylene oxide (EO) via Oxyfume-30 exposure $(30 \%$ $\mathrm{EO}$ and $70 \%$ carbon dioxide) for $8 \mathrm{~h}$ at $40^{\circ} \mathrm{C}$ and relative humidity of $30-80 \%$ at Acecil Central de Esterilização Comércio e Indústria (Campinas, SP, Brazil).

\section{Cell culture}

Immortalized human periodontal ligament fibroblasts purchased from Lonza Walkersville, Inc. (Walkersville, USA), identified by the company as Clonetics ${ }^{\mathrm{TM}}$ Human Fibroblast Cell System, were used. All cell culture procedures were performed under a laminar flow hood (Vertical Laminar Flow, Pachane, Piracicaba, Brazil), and all maintenance and sterility protocols of materials and solutions used followed. In the beginning of the culture process, a DHFL-AS sowing density of $5 \times 10^{5}$ cells, in $75 \mathrm{~cm}^{2}$ culture flasks was used (Corning, MO, USA), in a controlled environment of $37^{\circ} \mathrm{C}$ and $5 \%$ $\mathrm{CO}_{2}$ (Revco-Elite II, Rio de Janeiro, Brazil). The culture medium used was SCBM ${ }^{\mathrm{Tm}}$ (Lonza Walkersville, Inc. Walkersville, USA). For cell expansion, the $\mathrm{SCBM}^{\mathrm{TM}}$ culture medium was supplemented with SFB (Gibco, Gibco Industries Inc., USA), Recombinant Human Insulin, in $0.5 \mathrm{ml}$ vials, Gentamicin Sulfate and Amphotericin-B, in $0.5 \mathrm{ml}$ vials.

After supplementing the medium, the cells were expanded to $80 \%$ confluence in culture flasks, subcultures were performed in culture flasks to which $0.25 \%$ trypsin was used with $0.02 \%$ EDTA (Sigma Chemical Co., Saint Louis, MO, USA).

\section{Application of continuous static compression}

To mimic the pressure conditions during orthodontic movement, the following in vitro experiment was performed on a three-dimensional matrix, according to the method described by Nakajima., et al. [25]. Putting it briefly, the cells were seeded on a membrane of Chitosan and Xanthan already conformed to the bottom of 6-well plates (Figure 2).

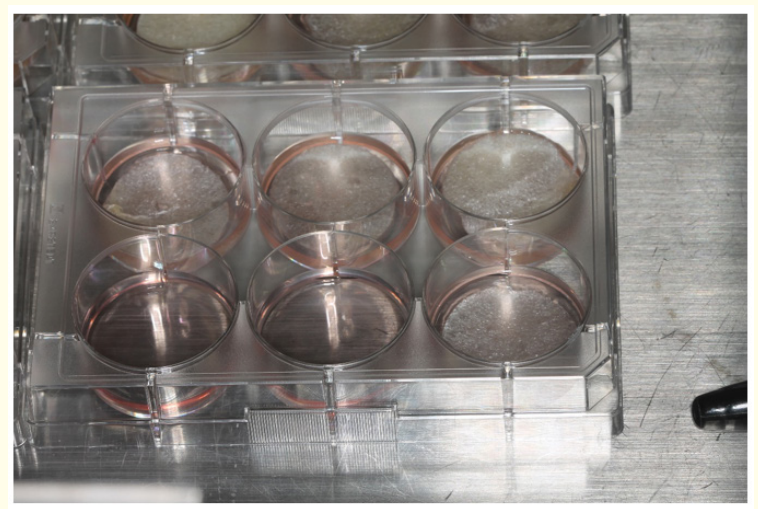

Figure 2: Periodontal ligament cells under cultivation on Chitosan and Xanthan membranes adapted to the bottom of the six-well plate.

The cells on the Chitosan and Xanthan membrane were pre-incubated in culture medium containing complete Alpha-MEM for six hours, before compression was applied. After that, weights $(27 \mathrm{~mm}$ stainless steel cylinders) were applied onto the membranes with a compression force of $4.0 \mathrm{~g} / \mathrm{cm}^{2}, 12 \mathrm{~g} / \mathrm{cm}^{2}, 24 \mathrm{~g} / \mathrm{cm}^{2}, 48 \mathrm{~g} / \mathrm{cm}^{2}$ for six hours, as shown in the model below (Figure 3 and table 1 ).

\section{Gene expression evaluation}

TaqMan Gene Expression Assays RT-PCR probe system was used to assess the presence of the target genes through PCR.

PCR amplification was performed in a thermocycler (QuantStudio $^{\mathrm{TM}} 5$ Digital ThermoFisher Scientific CA, USA). The advantage of real-time PCR is the possibility of accurately quantifying nucleic acids, with higher reproducibility, as it determines values during the exponential phase of the reaction.

\section{RNA extraction}

\section{RNA extraction and purification}

Total RNA was extracted with the PureLink ${ }^{\circledR}$ RNA Mini Kit Invitrogen kit (Carlsbad, Ca. 92008. USA), as per manufacturer's 


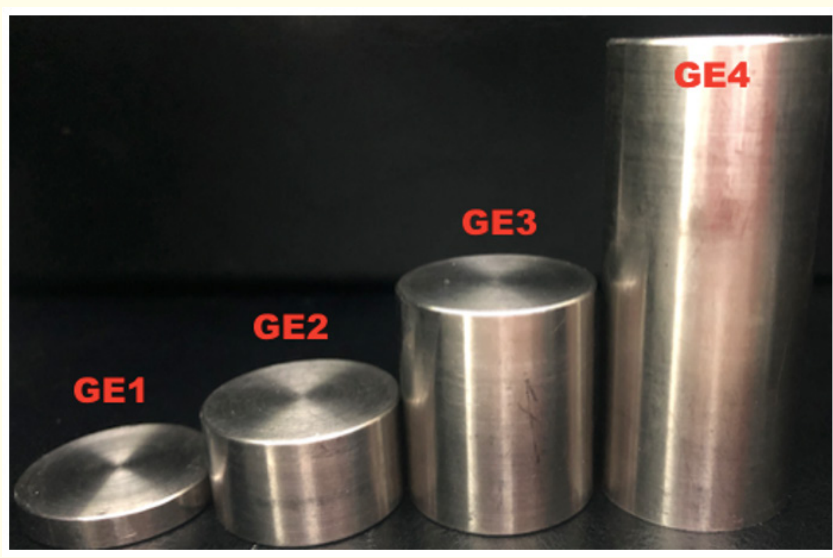

Figure 3: Static compression model used in experimental groups.

\begin{tabular}{|l|c|c|c|}
\hline Weight & Height & Diameter & Load \\
\hline $22 \mathrm{~g}$ & $0,5 \mathrm{~cm}$ & $2,7 \mathrm{~cm}$ & $4 \mathrm{~g} / \mathrm{cm}^{2}$ \\
\hline $68 \mathrm{~g}$ & $1,22 \mathrm{~cm}$ & $2,7 \mathrm{~cm}$ & $12 \mathrm{~g} / \mathrm{cm}^{2}$ \\
\hline $138 \mathrm{~g}$ & $3,0 \mathrm{~cm}$ & $2,7 \mathrm{~cm}$ & $24 \mathrm{~g} / \mathrm{cm}^{2}$ \\
\hline $274 \mathrm{~g}$ & $6,1 \mathrm{~cm}$ & $2,7 \mathrm{~cm}$ & $48 \mathrm{~g} / \mathrm{cm}^{2}$ \\
\hline
\end{tabular}

Table 1: Weight, height, diameter, and total load of stainless steel cylinders used in the compression model.

instructions. After treatment, the culture medium was collected, and the cells, as well as the chitosan and xanthan membrane were washed with Phosphate-buffered saline solution (PBS) once. PBS was removed and $300 \mu \mathrm{L}$ of lysis buffer plus $1 \% \beta$-mercaptoethanol added directly onto the plate. The cells were homogenized with the pipette and transferred to a $1.5 \mathrm{~mL}$ conical tube, where they were diluted in $70 \%$ ethanol (v/v) and applied into a silica microcolumn with guanidine isothiocyanate (which retains the total RNA), and centrifuged at 12,000g, for 15 seconds, at room temperature and the eluate discarded. Then, the microcolumn was washed with 700 $\mu \mathrm{L}$ of wash buffer I (Wash Buffer I) and washed twice with $500 \mu \mathrm{L}$ of wash buffer II (Wash Buffer II). Each washing step was followed by a 15 -second centrifugation at 10,000g after 2 minutes of centrifugation at $12,000 \mathrm{~g}$, the purified RNA adhered to the microcolumn was eluted in $20 \mu \mathrm{L}$ with ultrapure water, free of RNAses and DNAses.
RNA samples were decontaminated of the remaining genomic DNA using DNase I, Amplification Grade (Invitrogen). To do so, 16 $\mu \mathrm{L}$ of samples were incubated for 15 minutes at room temperature with $2 \mu \mathrm{L}$ of DNase I Buffer and $2 \mu \mathrm{L}$ of DNase I, Amplification Grade (1 unit $/ \mu \mathrm{L}$ ).

Total RNA was quantified using a NanoDrop spectrophotometer (Thermo Scientific, USA) to determine the concentration and degree of purity of the RNA for the synthesis of complementary DNA (cDNA) (Figure 4).

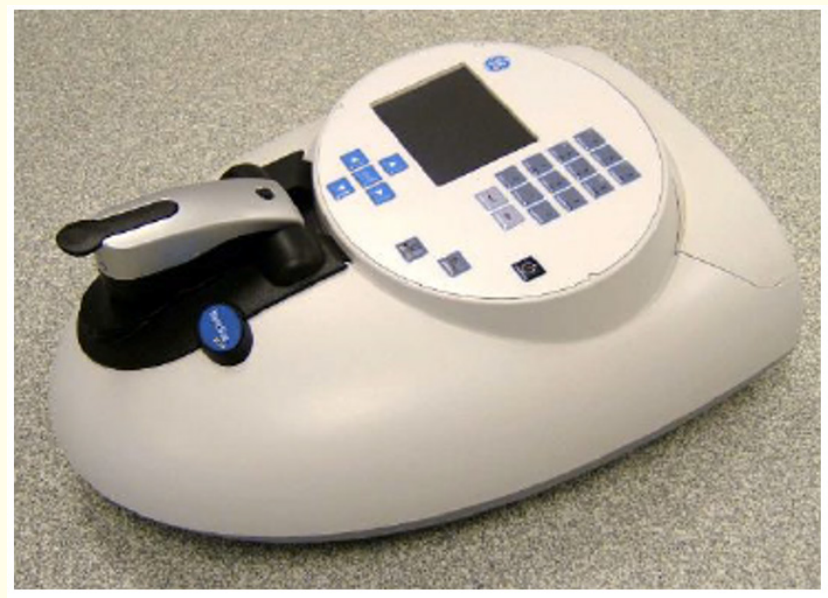

Figure 4: NanoDrop spectrophotometer to determine RNA concentration and purity.

\section{Synthesis of complementary DNA (cDNA)}

cDNA was synthesized with SuperScript ${ }^{\mathrm{TM}}$ III First-Strand Synthesis SuperMix (Invitrogen, USA).

\section{Real-time polymerase chain reaction}

Glyceraldehyde 3-phosphate dehydrogenase (GAPDH) was used as endogenous control of the RT-PCR reaction.

The RT-PCR reaction was performed using TaqMan ${ }^{\mathrm{TM}}$ Fast Advanced Master Mix (Applied Biosystems ${ }^{\mathrm{TM}}$ ). To evaluate the efficiency of TaqMan ${ }^{\mathrm{TM}}$ Gene Expression Assays (Applied Biosystem$\mathrm{s}^{\mathrm{TM}}$ ), different concentrations of cDNA (25 ng, $12.5 \mathrm{ng}, 6.25 \mathrm{ng}, 3.12$ ng and $1.56 \mathrm{ng}$ ) were used for each TaqMan, in the same concentration $(1 \mu \mathrm{L})$, in triplicates. Cts and initial cDNA concentrations were 
used to develop an efficiency curve, where higher concentrations should proportionally generate lower Ct values. After the efficiency curves were obtained, $6.25 \mathrm{ng}$ was determined to be the optimum concentration. For each reaction, 6.25 ng cDNA, $5 \mu \mathrm{L}$ of TaqMan ${ }^{\mathrm{TM}}$ Fast Advanced Master Mix (Applied Biosystems ${ }^{\mathrm{TM}}$ ), $1 \mu \mathrm{L}$ of TaqMan and RNAse-free water were added to a final volume of $10 \mu \mathrm{L}$. All reactions were performed in triplicate. After the reaction was prepared, QuantStudio $^{\mathrm{TM}} 5$ Real-Time PCR (Applied Biosystems ${ }^{\mathrm{TM}}$ ) was used. The amplification cycle consisted of $95^{\circ} \mathrm{C}$ for 10 minutes, followed by 40 cycles of $95^{\circ} \mathrm{C}$ for 15 seconds, $60^{\circ} \mathrm{C}$ for 1 minute, and $72^{\circ} \mathrm{C}$ for 30 seconds. The dissociation curve was made with 1 cycle of $95^{\circ} \mathrm{C}$ for 1 minute, $60^{\circ} \mathrm{C}$ for 30 seconds, and $95^{\circ} \mathrm{C}$ for 30 seconds. The number of cycles that pass the $\mathrm{Ct}$ threshold, in which all samples can be compared, was determined from the amplification curves generated. The relative quantification method was used with these values, through which the results obtained from the analysis of the genes in question were compared with the reference gene - GADPH. This way, arbitrary levels of mRNA were expressed as a difference of " $n$ " times in relation to the gauge (control group). Relative genes expression was calculated using the 2- $\Delta \Delta \mathrm{Ct}$ method, where: $\mathrm{Ct}$ : indicates the number of the cycle in which the amount of the amplified gene in question reaches a fixed threshold; the lower the numerical value of $\mathrm{Ct}$, the faster the number of targeted copies was achieved:

- $\Delta \mathrm{Ct}$ : Normalization in relation to the constitutive expression gene, obtained from the difference between the $\mathrm{Ct}$ of the gene in question and the $\mathrm{Ct}$ of the reference gene (in this case, GAPDH) for each sample;

- $\Delta \Delta \mathrm{Ct}$ : Control group $\Delta \mathrm{Ct}$ average $-\Delta \mathrm{Ct}$ of each gene for each sample.

\section{Statistical analysis}

All data were analyzed through one-way analysis of variance (ANOVA), Tukey test corrected. Values of $\mathrm{p}<0.05$ were considered significant and marked with *.

\section{Results}

To evaluate gene expression of periodontal ligament fibroblasts a compression model was developed, consisting of $27 \mathrm{~mm}$-diameter stainless steel cylinders placed on the center of each culture plate well containing a chitosan and xanthan membrane. Polymerase Chain Reaction (PCR) was used to evaluate the presence of target genes, using TaqMan Gene Expression Assays RT-PCR.
The TaqMan Gene Expression Assays RT-PCR method displayed no gene expression of the nuclear factor $\kappa \mathrm{B}$ ligand receptor activator (RANKL), as shown in table 2.

\begin{tabular}{|l|c|}
\hline Groups & RANKL Relative Expression \\
\hline CG & $0,03 \pm 0,01$ \\
\hline EG1 & $0,04 \pm 0,01$ \\
\hline EG2 & $0,09 \pm 0,02$ \\
\hline EG3 & $0,08 \pm 0,01$ \\
\hline EG4 & $0,03 \pm 0,01$ \\
\hline Value of $p$ & 0,8 \\
\hline
\end{tabular}

Table 2: Mean and standard deviation of the values of the triplicates of RANKL expression. Values in relative expression (VER) obtained via RT-PC.

CG (control group); EG1 (experimental group 1- 4g/ $\mathrm{cm}^{2}$ ); EG2 (experimental group 2- $12 \mathrm{~g} / \mathrm{cm}^{2}$ ); EG3 (experimental group 3- 24 $\mathrm{g} / \mathrm{cm}^{2}$ ); EG4 (experimental group 4- $\left.48 \mathrm{~g} / \mathrm{cm}\right)^{2}$. RANKL ANOVA test with $\mathrm{p}<0.05$.

The TaqMan Gene Expression Assays RT-PCR method displayed no gene expression of the receptor activator of nuclear factor $\kappa \mathrm{B}$ (RANK), as shown in table 3.

\begin{tabular}{|l|c|}
\hline Groups & RANK Relative expression \\
\hline CG & $0,02 \pm 0,01$ \\
\hline EG1 & $0,07 \pm 0,02$ \\
\hline EG 2 & $0,03 \pm 0,01$ \\
\hline EG 3 & $0,02 \pm 0,01$ \\
\hline EG 4 & $0,03 \pm 0,01$ \\
\hline value of $p$ & 0,8 \\
\hline
\end{tabular}

Table 3: Mean and standard deviation of the values of the triplicates of RANK expression. Values in relative expression (VER) obtained via RT-PC.

CG (control group); EG1 (experimental group 1- 4 g/cm²); EG2 (experimental group 2- $12 \mathrm{~g} / \mathrm{cm}^{2}$ ); EG3 (experimental group 3- 24 $\mathrm{g} / \mathrm{cm}^{2}$ ); EG4 (experimental group $4-48 \mathrm{~g} / \mathrm{cm}^{2}$ ). RANK ANOVA test with $\mathrm{p}<0.05$. 
After reading the gene expression in RT-PCR, the analysis of osteoprotegerin expression data was conducted whose results are shown in table 4.

\begin{tabular}{|l|c|}
\hline Groups & OPG Relative expression \\
\hline CG & $0,5 \pm 0,1$ \\
\hline EG1 & $0,6 \pm 0,1$ \\
\hline EG2 & $1.5 \pm 0,2$ \\
\hline EG3 & $0.8 \pm 0,1$ \\
\hline EG4 & $0,6 \pm 0,1$ \\
\hline Value of $p$ & $0,03^{*}$ \\
\hline
\end{tabular}

Table 4: Average and standard deviation values of the triplicates of the osteoprotegetin (OPG) gene expression. Values in relative expression (VER) obtained via RT-PCR.

CG (control group); EG1 (experimental group 1- 4 g/ $\mathrm{cm}^{2}$ ); EG2 (experimental group 2- $12 \mathrm{~g} / \mathrm{cm}^{2}$ ); EG3 (experimental group 3- 24 $\mathrm{g} / \mathrm{cm}^{2}$ ); EG4 (experimental group $4-48 \mathrm{~g} / \mathrm{cm}^{2}$ ). OPG ANOVA test with $\mathrm{p}<0.05$ marked with*.

\section{Discussion}

The periodontal ligament is a highly differentiated tissue, with fast turnover and high remodeling rates. Even though periodontal fibroblasts are predominant, other cells can also be found in this tissue, such as undifferentiated and epithelial mesenchymal cells. Not only are periodontal ligament cells responsible for maintaining the periodontal ligament, but also the alveolar bone, and root cementum [19]. The regenerative potential of the periodontal ligament is linked to the functions of periodontal fibroblasts [16]. Such cells are the most abundant in the periodontal ligament and known to modulate alveolar bone remodeling processes through the production of enzymes and active cytokines, including RANK (Receptor Activator of Nuclear Factor Kappa), RANKL (Ligand) and OPG (Osteoprotegerin), Nishijima., et al. [26]; Kook., et al. [16], when subjected to mechanical or physiological stress.

Osteoprotegerin (OPG) is the soluble attraction receptor of RANKL which can suppress the link between RANK and RANKL and block its effects on osteoclastogenesis and bone formation, whereas soluble RANKL is released from the plasma membrane by a disintegrin metalloprotease converter-TNF- $\alpha$, with soluble RANKL and membrane-bound RANKL regulating osteoclastogen- esis and bone formation $[10,16,18,26]$. Due to the difficulty in performing in vivo experiments, Kang., et al. [12], Nakajima., et al. [25] and Nishijima., et al. [26] used compressive models on periodontal fibroblasts to investigate the mechanism by which mechanical signals are transduced into biological signals, which regulate bone homeostasis via periodontal ligament.

Most cells in a native in vivo environment are integrated into a 3D gel, hydrated, flexible and porous, surrounded by other cells, called extracellular matrix (ECM). In this study, to reconstruct a model that more closely represents the natural structure and functions of tissues in vivo, a three-dimensional (3D) cellular compression model was developed to assess in vitro cellular events that occur in vivo when cells are subjected to a compressive force. Heckler., et al. [8] developed a three-dimensional (3D) model; in which collagen gels seeded with human periodontal ligament fibroblasts displayed cell proliferation, viability, and the appearance of a possible contractile phenotype, replicating the restricted condition of the human periodontal ligament in vivo.

To replicate the in vivo environment, cells must adhere and grow properly in three-dimensional (3D) scaffolds or substrates, thus facilitating cell-cell contact and expression of the expected phenotype $[7,22]$. Cells cultured on a 3D matrix represent the natural structure and function of tissues in vivo more closely with respect to the physiology, shape, and environment of the cell $[5,23,33]$.

Mechanotransduction can be defined as the process of producing a biochemical reaction from a mechanical stimulus. Biochemical chain reactions induced by mechanical stimuli act at cellular level and can inhibit apoptosis, increase cell proliferation, alter cell migration, among other effects. For example, while chewing, the mechanical forces transferred onto the teeth are dissipated through the periodontal ligament. Histological studies have shown that while submitted to this force the tissue around the teeth display tension associated with bone formation, and compression on the other side, thus inducing bone resorption [21]. Research in the field of cell biology often seeks to identify which molecules are present during this process of cell differentiation when subjected to different types of loads during tooth movement. High loads can reduce cell viability, causing apoptosis or significant tissue damage, whereas cells in periodontal tissue can develop osteoblastic activity when subjected to mechanical stress [32]. An indicator of 
this remodeling is the expression of osteoclastogenesis markers: osteoprotegerin (OPG), Receptor Activator of Nuclear kB (RANK) and Receptor Activator of Nuclear kB ligand (RANKL) responsible for cell differentiation, proliferation, and the expression of the extracellular matrix [27].

The RANK/RANKL/OPG system plays a key role in bone resorption and can be modified by osteoblasts, fibroblasts, and osteoclasts $[13,20]$. RANKL facilitates bone resorption through osteoclasts and activates bone maturation [34]. Osteoblasts and fibroblasts also express OPG, a balancing protein, which acts as a receptor for RANKL by inhibiting bone resorption.

The collagen framework has been used in tissue engineering because it has biocompatibility, biodegradability, and low antigenicity $[1,17]$. However, certain properties of three-dimensional collagen frameworks have limited their use due to their mild immunogenicity, lack of mechanical resistance and stability to hydration, in addition to the high cost of pure collagen [29]. Different types of natural or synthetic polymeric materials have been used in the production of substrates, or frameworks as structural models to direct cell growth. Properties such as biocompatibility, mechanical resistance, low toxicity, fluid absorption capacity, pore size and shape, are substantially important in the selection of the raw materials used to produce substrates or frameworks $[2,3]$.

In the present study, the porous chitosan and xanthan membrane was developed as a three-dimensional (3D) scaffold or substrate, corroborating the work of Uygun., et al. [30], who reported membrane thickness as an important factor to achieve greater cell proliferation and differentiation. Varoni., et al. [31] who evaluated periodontal regeneration in nude mice, using porous and dense chitosan membranes, observed high biocompatibility, cell growth and vascularization within the porous membrane, suggesting a promising candidate for periodontal regeneration.

Li., et al. [18], used a (3D) model comprised of poly-L-glycolic polymer and poly-L-lactic acid matrix seeded with periodontal ligament cells subjected to compression force. The relationship between OPG and RANKL was significantly decreased for 3 and 6 hours, whereas, OPG expression decreased after 3 hours, increased for 6 hours, and was significantly expressive after 12 hours.

Mitsuhashiet., et al. [24] observed that recombinant protein 70 (HSP70) can modulate the expression of TNFx and RANKL mRNA in periodontal ligament cells during compression, depending on time and magnitude. Li., et al. [18] evaluated a three-dimensional model with periodontal ligament tissue using a thin sheet of lacticco-glycolic acid as a framework. After applying the compression force of $25 \mathrm{~g} / \mathrm{cm}^{2}$ for 6, 24 and 72h, an increase in RANKL expression was observed for 6 and 24h, and a decrease in OPG expression. A decrease in RANKL expression and increase in OPG expression were observed, as the time increased to $72 \mathrm{~h}$. However, when Nishijima., et al. [26] and Nakagima., et al. [25] used compressive models in monolayer (2D) human periodontal fibroblast cultures, an increase in RANKL expression and a decrease in OPG expression were observed, under compression force of $4 \mathrm{~g} / \mathrm{cm}^{2}$ for a period of $48 \mathrm{~h}$. In those two studies, the results showed that the compression force magnitude and elapsed time are directly linked to increase in RANKL production. On the other hand, when Kanzaki., et al. [11] evaluated RT-PCR expression profiles of micro RNAs in periodontal fibroblasts submitted to tension strength and compression, they observed that the expression of certain micro RNAs increased regardless of time under stress, whereas other micro RNAs increased their expression only at specific times. This is in line with Kanzaki., et al. [10], Nishijima., et al. [26], Kook., et al. [15] and Kook., et al. [16] who suggested that periodontal ligament fibroblasts under stress increase the expression of RANKL and decrease the expression of OPG, thus facilitating bone resorption during tooth movement. There is evidence that cells in 2D and 3D cultures can display different levels of gene expression, suggesting a link to the extracellular matrix which can influence cellular responses to stress $[10,14,15]$.

In this study, OPG expression was found in all groups evaluated, however, a statistical difference was only found in the values for EG2, which used a load of $12 \mathrm{~g} / \mathrm{cm}^{2}$. The results of this study in relation to EG2 were similar to those found by Jainru., et al. [9] who used a load of $25 \mathrm{~g} / \mathrm{cm}^{2}$ for 3, 6 and 12 hours, obtaining a lower expression of OPG after three hours, and a greater expression of OPG after six hours of compression, thus concluding that long-term static compression would increase the expression of OPG. In the present study, there was a decrease in the expression of OPG in EG4, submitted to a load of $48 \mathrm{~g} / \mathrm{cm}^{2}$. Work by Li., et al. [18] showed an increase in the expression of RANKL after six hours of mechanical compression $\left(25 \mathrm{~g} / \mathrm{cm}^{2}\right)$. The present study, however, when using the model proposed, found no expression of RANKL, but of OPG.

Citation: Andrea Cristina Baptista Coelho de Faria., et al. "Gene Expression of the RANK/RANKL/OPG System on a Three-Dimensional Culture of Human Periodontal Fibroblasts Under Continuous Compression". Acta Scientific Dental Sciences 5.10 (2021): 91-99. 
OPG is a gene that responds differently to mechanical stimuli in 3D cultures, when compared to 2D, which suggests that the bound to the extracellular matrix may influence cellular responses.

\section{Conclusion}

The load of $12 \mathrm{~g} / \mathrm{cm}^{2}$ for 6 hours in a three-dimensional culture of periodontal fibroblasts showed greater expression of OPG.

\section{Bibliography}

1. Alves LB., et al. "Expression of osteoblastic phenotype in periodontal ligament fibroblasts cultured in three-dimensional collagen gel". Journal of Applied Oral Science - SciELO 23.2 (2015): 206-214.

2. Bellini MZ., et al. "Comparison of the properties of compacted and porous lamelar chitosan-xanthan membranes as dressings and scaffolds for the treatment of skin lesions". Journal of Applied Polymer Science 125 (2012): 421-431.

3. Bellini MZ., et al. "Combining Xanthan and chitosan membranes to multipotent mesenchimal stromal cells as bioactive dressings for dermo-epidermal wounds". Journal of Biomaterials Applications 29.8 (2015): 1155-1166.

4. Chen FM and Jin Y. "Periodontal tissue engineering and regeneration: current approaches and expanding opportunities". Tissue Engineering. Part B, Reviews 16 (2010): 219-255.

5. Chevallay B and Herbage D. "Collagen-based biomaterials as 3D scaffold for cell cultures: applications for tissue engineering and gene therapy". Medical and Biological Engineering and Computing 38 (2000): 211-218.

6. Daley WP., et al. "Extracellular matrix dynamics in development and regenerative medicine". Journal of Cell Science 121 (2008): 255-264.

7. Griffith LG and Naughton G. "Tissue engineering-current challenges and expanding opportunities". Science 295 (2002): 1009-1014.

8. Heckler AF., et al. "Development of a three-dimensional in vitro model system to study orthodontic tooth movement". Archives of Oral Biology 58 (2013): 498-410.
9. Jianru YI., et al. "Static compression regulates OPG expression in periodontal ligament cells via the CAMK II pathway". Journal of Applied Oral Science - SciELO 23.6 (2015): 549-554.

10. Kanzaki H., et al. "Periodontal ligament cells under stress induce osteoclastogenesis by Receptor Activator of Nuclear Factor $\mathrm{\kappa B}$ Ligand up-regulation via prostaglandin E2 synthesis". Journal of Bone and Mineral Research 17 (2002): 210-220.

11. Kanzaki H., et al. "Compression and tension variably alter Osteoprotegerin expression via miR-3198 in periodontal ligament cells". BMC Molecular and Cell Biology 20.6 (2019): 187.

12. Kang KL., et al. "Bioinformatic analysis of responsive genes in two-dimension and three-dimension cultured human periodontal ligament cells subjected to compressive stress". Journal of Periodontal Research 48 (2013): 87-97.

13. Kearns AE., et al. "Receptor activator of nuclear factor kappaB ligand and osteoprotegerin regulation of bone remodeling in health and disease". Nature Reviews Endocrinology 29 (2008): 155-192.

14. Kim JW., et al. "Effects of compressive stress on the expression of IL-1 $\beta$, RANKL and OPG mRNA in periodontal ligament cells". The Korean Journal of Orthodontics 39.4 (2009): 248-256.

15. Kook SH., et al. "Mechanical force inhibits osteoclastogenic potential of human periodontal ligament fibroblasts through OPG production and ERK-mediated signaling". Journal of Cellular Biochemistry 106 (2009): 101-119.

16. Kook SH., et al. "Human periodontal ligament fibroblasts stimulate osteoclastogenesis in response to compression force through TNF- $\alpha$-mediated activation of CD 4+ T cells". Journal of Cellular Biochemistry 112 (2011): 2891-2801.

17. Lee YH., et al. "Differential gene expression of periodontal ligament cells after loading of static compressive force". Journal of Periodontology 41 (2007): 446-452.

18. Li Y., et al. "Expression of osteoclastogenesis inducers in a tissue model of peri- odontal ligament under compression". Journal of Dental Research 90 (2011): 115-120.

19. Li M., et al. "Effects of mechanical forces on osteogenesis and osteoclastogenesis in human periodontal ligament fibroblasts". Bone and Joint Research 8 (2019): 19-31. 
20. Lossdorfer S., et al. "Induced changes in RANKL and OPG expression by human PDL cells modify osteoclast biology in a co-culture model with RAW 264.7 cells". Clinical Oral Investigations 15 (2011): 941-952.

21. Meikle MC. "The tissue, cellular, and molecular regulation of orthodontic tooth movement: 100 years after Carl Sandstedt". European Journal of Orthodontics 28 (2006): 221-240.

22. Minuth WW., et al. "Tissue engineering: generation of differentiated artificial tissues for biomedical applications". Cell and Tissue Research 291 (1998): 1-11.

23. Mueller-Klieser W. "Three-dimensional cell cultures: from molecular mechanisms to clinical applications". American Journal of Physiology 273 (1997): 1109-1123.

24. Mitsuhashi M., et al. "Effects of HSP70 on the compression force-induced TNF and RANKL expression. In human periodontal ligament cells". Inflammation Research 60 (2011): 187-194.

25. Nakajima R., et al. "Effects of compression force on fibroblast growth fator-2 and receptor activator of nuclear fator kappa B ligand production by periodontal ligament cells in vitro". Journal of Periodontal Research 43 (2008): 168-173.

26. Nishijima Y., et al. "Levels of RANKL and OPG in gingival crevicular fluid during orthodontictooth movement and effect of compression force on releases from periodontal ligament cells in vitro". Orthodontics and Craniofacial Research 9 (2006): 6370.

27. Romer P. "The molecular mechanism behind bone remodelling: A review". Clinical Oral Investigations 13 (2009): 355-362.

28. Sant'ana ACP., et al. "Culture and caractherization of human derived periodontal ligament cells". Revista da Faculdade de Odontologia de Bauru 10 (2002): 134-140.

29. Souza RFB., et al. "Mechanically-enhanced polysaccharidebased scaffolds for tissue engineering of soft tissues". Materials Science and Engineering C 94 (2019): 364-375.

30. Uygun BE., et al. "Membrane thickness in an important variable in membrane scaffolds: influence of chitosan membrane structure on the behavior of cells". Acta Biomater 6 (2010): 2126-2131.

31. Varoni EM., et al. "Chitosan-Based Trilayer Scaffold for Multitissue Periodontal Regeneration". Journal of Dental Research 97.3 (2018): 303-311.

32. Wescott DC., et al. "Osteogenic gene expression by human periodontal ligament cells under cyclic tension". Journal of Dental Research 86 (2007): 1212-1216.

33. $\mathrm{Xu}$ T., et al. "Electrophysiological characterization of embryonic hippocampal neurons cultured in a 3D collagen hydrogel". Biomaterials 30 (2009): 4377-4383.

34. Yasuda H., et al. "Osteoclast differentiation factor is a ligand for osteoprotegerin/osteoclastogenesis inhibitory factor and is identical to TRANCE/RANKL". Proceedings of the National Academy of Sciences of the United States of America 95 (2009): 3597-3502.

\section{Volume 5 Issue 10 October 2021 \\ (C) All rights are reserved by Andrea Cristina Baptista Coelho de Faria, et al.}

